\title{
Effects of Age, Gender, Familiarity with the Content, and Exposure Time on Cybersickness in Immersive Head-mounted Display Based Virtual Reality
}

\author{
Katharina Petri*, Kuno Feuerstein, Svea Folster, Florian Bariszlovich, Kerstin Witte \\ Otto-von-Guericke-University Magdeburg, Institute III: Sports Science, Department of Sports Engineering and \\ Movement Science, Germany \\ "Corresponding Author \\ Katharina Petri \\ Otto-von-Guericke-University Magdeburg \\ Institute III: Sports Science, Department of Sports Engineering and Movement Science \\ Germany \\ Email: katharina.petri@,ovgu.de
}

Received:17 February 2020; | Revised:11 March 2020; | Accepted:04 June 2020

\begin{abstract}
Although several studies have been conducted in the field of cybersickness, triggering factors have not been conclusively identified. We performed two cross-sectional studies on cybersickness, in which seated participants watched karate specific content in a virtual reality (VR) app with a head-mounted display. We analyzed the effects of the factors "age" (three age levels), "familiarity with the content / expertise" (karatekas, non-karatekas), "gender" and "exposure time" (analysis over 10 and 20 minutes stay in VR) using the Simulator Sickness Questionnaire, biofeedback (parameters: skin conductance and heart rate) and verbal reports of estimated symptoms. All analyzed factors had an effect on cybersickness. We observed that adults over 60 years and participants who are not familiar with the sports specific content (here nonkaratekas) are more prone to cybersickness with exposure times of 20 minutes compared to 10 minutes. We detected a significant gender difference in the verbal estimation of cybersickness as women had more problems, while men had no symptoms at all. A duration of 10 minutes in VR is bearable in all analyzed groups. For healthy men and persons being familiar with the content shown, 20 minutes are also doable. However, all detected symptoms were only moderate and no dropout occurred.
\end{abstract}

Keywords:Virtual environment, Virtual reality app, Head-mounted display, Biofeedback, Simulator sickness questionnaire

\section{Introduction}

Virtual reality (VR) is an often-used training tool in many areas, such as driving and flight simulations, military, entertainment, education and certification ${ }^{[1,2]}$, medicine and health (e.g. applications of automatic CAD systems, ${ }^{[3]}$ or to benefit outcome in biomedical sciences ${ }^{[4]}$ ), as well as sports ${ }^{[5-8]}$. Nowadays, head-mounted displays (HMDs) are frequently used for creating immersive and interactive VR because these lightweight devices are quite cheap and easy to use ${ }^{[9]}$. Although problems with cybersickness can occur, these problems are hardly reported precisely ${ }^{[10]}$. 
Cybersickness is defined as a physical discomfort due to the stay in VR. Symptoms comprise nausea, eyestrain, disorientation, dizziness, ataxia and cold sweating. There are four theories existing to explain the occurrence of cybersickness: sensory conflict theory, poison theory, postural instability theory, and vergence-accomodation conflict, but the widely accepted theory is a conflict between the visual and the proprioceptive sensors. The user seems to be in motion while he is stationary or the other way round. In recent reviews, occurrence of cybersickness, symptoms and possible solution approaches, are discussed [11-14]. Rotations and especially large head rotations can cause cybersickness because of delays in adequate scene adaptations according to the user's perspective ${ }^{[13,15]}$. Therefore, cybersickness is a result of dynamic changes of scale ${ }^{[16]}$.

Some studies found that cybersickness is more pronounced in HMDs than screen-based VR (e.g. ${ }^{17}$, ${ }^{18]}$ ), such as CAVEs or powerwalls due to the limited field of view compared to normal seeing through the eyes in reality $[13,19] .{ }^{[20]}$ compared cybersickness between HMD and CAVE and found more symptoms of cybersickness in HMD. That it is in line with ${ }^{[18,21]}$ who detected that symptoms in HMDs occurred in $80 \%$ of the cases. However, the technical progress in HMDs is quite fast and thus, new HMDs become better and better ${ }^{[2]}$. In that context, it was found that karate athletes preferred the HMD (Oculus Rift, DK2) over a CAVE due to a greater immersion. However, no symptoms of cybersickness were found in HMD or in CAVE [22]. Three different approaches of HMDs are existing: monoscopy (identical pictures for both eyes), bioptic (one display for both eyes) and stereoscopy (two slightly different pictures for both eyes). As most HMDs applied in the field of sports are based on stereoscopy ${ }^{[23]}$, we also used an HMD of this kind.

Factors supporting cybersickness can be delays and low frame rates ${ }^{[24]}$, exposure time to $\mathrm{VR}{ }^{[2,25]}$, as well as individual factors, such as gender, age, illness, position in the VR and interaction possibilities $[2,13]$. For instance, women are more prone to cybersickness [9] but on the other hand often recover faster compared to men ${ }^{[26]}$. However, the effect of gender is not clarified. While some studies (e.g. ${ }^{[26]}$ ) found a gender difference in VR, others (e.g. ${ }^{[2]}$ ) did not. Children at the age of 2 to 12 years are also thought to be more vulnerable to cybersickness than adults. At the age of 12 to 21 years, cybersickness decreases rapidly, and from this age until the age of 50 years, cybersickness is thought to disappear. Sick persons are also more susceptible to cybersickness than healthy persons are. Further, it was found that seated persons feel better than standing persons in VR ${ }^{[12]}$ but the best effects on cybersickness were seen by providing the possibility of free movements and control in the VR [13, 19,27].

Symptoms of cybersickness can be assessed by validated questionnaires, e.g. Simulator Sickness Questionnaire (SSQ) ${ }^{[28]}$, postural sway analysis and biofeedback measurements, such as skin temperature, skin conductance, blood pressure and heart rate ${ }^{[13]}$. It is well known that increasing heart rates, as well as a change in skin pallor, skin conductance and body temperature are correlated with the severity of symptoms ${ }^{[1,29,30]}$. Furthermore, there is a correlation of rapid eye movements and symptoms of headache and fatigue ${ }^{[1]}$. However, due to the complexity of the nervous system, it is still unclear which parameters can be used for precise identification and prediction of cybersickness ${ }^{[1,31]}$. According to ${ }^{[1,2,29]}$, there is further need to identify how several physiological parameters and cybersickness are correlated. Unfortunately, there is a lack in standards to evaluate virtual environments and to assess cybersickness. Furthermore, safety standards in VR are missing and it is still not possible to predict the occurrence of cybersickness correctly ${ }^{[9,13]}$. Therefore, we chose several methods for the assessment of cybersickness: validated questionnaires, verbal reports and biofeedback measurements.

In previous VR sports interventions with HMD application, in which experienced athletes had to respond sports specifically to karate attacks (e.g. [32, 33]), no symptoms of cybersickness were found. Thus, the possibility of natural movement behavior can be important to reduce cybersickness. Furthermore, in studies, in which athletes used HMDs for tactical training ${ }^{[34]}$ and for observational learning ${ }^{[35]}$ in a seated position, only slight problems with cybersickness occurred. In the mentioned studies, the athletes were familiar with the sports specific content shown in the VR. 
In most of the VR sports interventions, the session length was restricted to ten minutes (e.g. ${ }^{[36]}$, for review see $\left.{ }^{[7]}\right)$. It is unclear if a longer exposure time in VR would also be possible, which would be interesting for athletes who are unable to perform the physical training due to schedule issues or injuries.

In recent studies with senior adults (e.g. VR in rehabilitation, ${ }^{[37]}$ ), and especially with HMD application [38], no or only slight problems with cybersickness were found. Furthermore, although experiences with modern technology are rare, this participant group had the same motivation to use VR as young adults. However, further research is needed to confirm these results ${ }^{[38]}$.

In the present work, we used a VR app, which has previously been applied for observational learning ${ }^{[35]}$. Such head mounted smartphone technology is quite user friendly ${ }^{[39]}$. The test coordinator (or the participants) can start the app on the smartphone and connect it with an HMD. Thus, the VR application can be used wherever wireless internet is available and independently from other persons, such as coaches, opponents or teammates, and from further (expensive) technology.

Although several VR interventions are existing in sports and rehabilitation, we still see a research gap in the identification of relevant factors, which are responsible for the appearance of cybersickness. Already ${ }^{[17]}$ identified gender, content type and exposure time in VR as relevant factors on sense of presence and cybersickness. A further study [2] analyzed these three factors on sense of presence and cybersickness and compared different types of immersive content $\left(360^{\circ}\right.$ video versus $360^{\circ}$ artificial virtual environment). They could not find a significant effect of gender, exposure time and content. However, the recorded environment was a daily situation and not a sports specific scenario. Additionally, only short duration times of 1,3,5, and 7 minutes were examined. Thus, further research is needed to analyze longer exposure times and other content with newer HMDs ${ }^{[2]}$. Therefore, we intended to extend the previous described study. Analyses towards factors of cybersickness have not been carried out with a VR app before. The results of such investigations can further be important to design concrete recommendations for VR interventions, both in recreational and high- performance sports, as well as for sports for the elderly and rehabilitation programs.

We performed two cross-sectional studies using a VR app and an HMD, with which participants (karate-athletes and non-karate athletes of several ages) observed karate attacks. We examined the factors "age", "gender" and "familiarity with the content", as well as "exposure time to VR (10 versus 20 minutes)" by applying questionnaires (study 1), as well as biofeedback analyses and verbal reports of symptoms (study 2). The factor "familiarity with the content" means that we compare participants with previous karate experience with those who did not perform karate before. Based on previous literature ${ }^{[2,29]}$, we did not expect effects of "gender", "age" and "familiarity with the content" on cybersickness, but we expected an increase of cybersickness with increasing exposure time.

\section{Methods}

Two studies were performed in accordance with the declaration of Helsinki of 1975, revised in 2008. All participants were informed about the aim and the procedure of the study and gave their written consent prior to the beginning.

\subsection{VR app}

In both experiments, we used the VR app Binoo (www.edu2vr.com, ${ }^{[40]}$ ) which was previously used in an intervention study for observational learning ${ }^{[36]}$. Athletes were seated on a rotating chair and watched a karate attack being performed by a virtual character. The athletes were allowed to control the perspective and the velocity of the attack executions by buttons around the character, which they had to fixate using a grey point that represented the gaze. The virtual environment was developed using a $360^{\circ}$ image of a martial arts gym with a fighting area. The character was created based on movements of two high-skilled male karate athletes with international experience (black belt, 2nd Dan, shotokan style, German Karate Federation DKV), which were recorded with a motion capturing (Vicon, Oxford, UK and ART, Weilheim, Germany, $120 \mathrm{~Hz}$ ). The app was downloaded for free in the playstore or appstore and started in the VR mode on the 
smartphone of the test coordinators. Then, the smartphone (Huawei P10 Lite in study 1, Iphone 6s in study 2) was latched into an HMD (Renkforce-
RF, Hirschau, Germany) and the participants navigated through the app independently using their head movements (Fig.1).

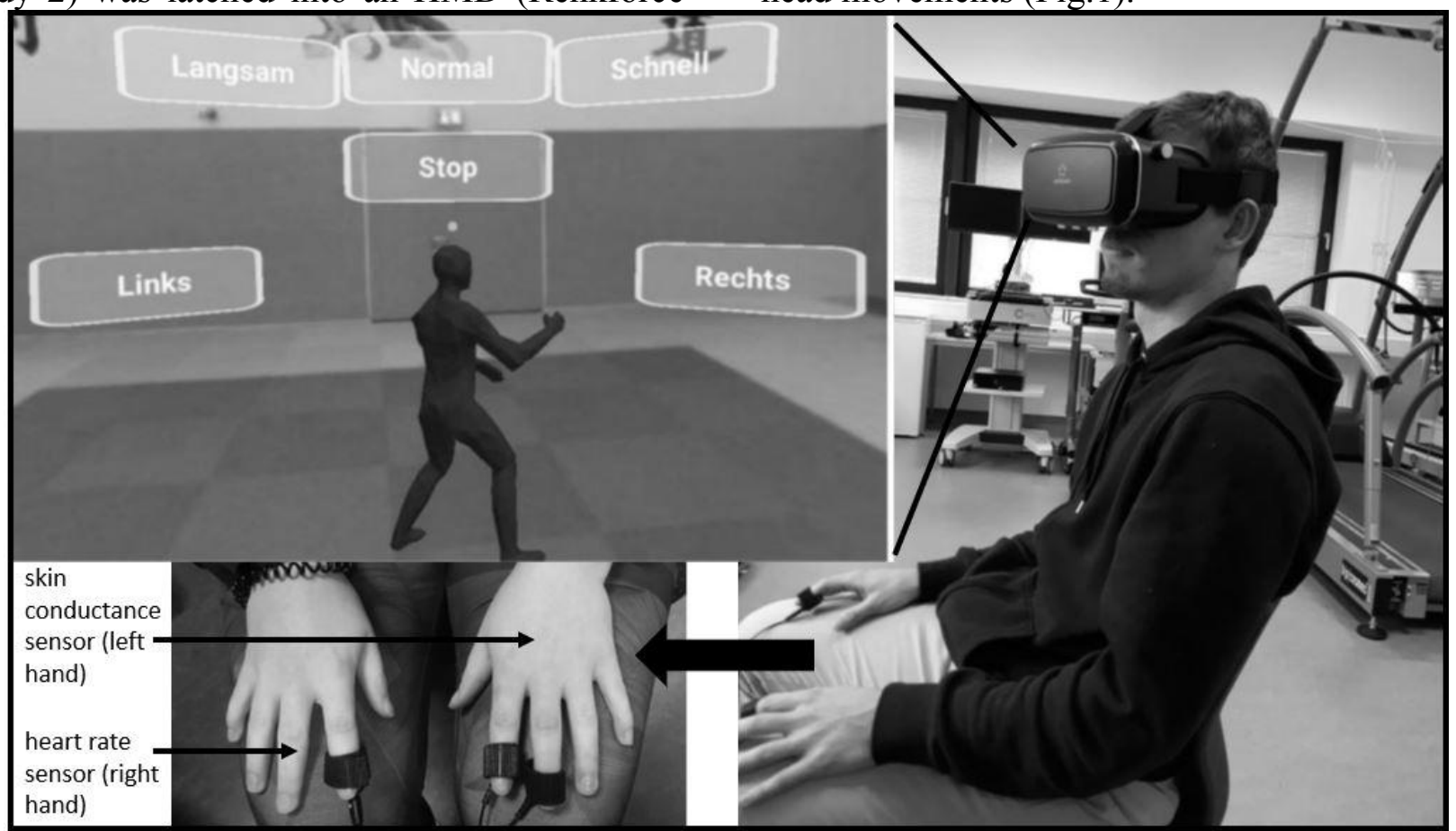

Figure 1: Procedure of both studies: Seated participants watching karate movements of a virtual character using a VR app and a head-mounted display. Using their gaze point, they could navigate through the VR independently and control the characters movement execution (change of perspective and speed by clicking on the buttons around the virtual character using their gaze point). In study 2, biofeedback sensors were placed on the users' hands. Only movements with the head but not with the rest of the body were allowed.

\subsection{Study 1}

In study 1 , we aimed to analyze the influence of age, familiarity with the content / expertise, and exposure time in VR on cybersickness using the validated Simulator Sickness Questionnaire (SSQ, ${ }^{[28]}$ ) as a standardized tool ${ }^{[4]}$. Therefore, we compared three age levels (18-35 years versus 3660 years versus over 60 years) in karate athletes. Furthermore, we compared karate-athletes with non-athletes.

\subsubsection{Participants}

Forty $(n=40)$ healthy participants with normal or corrected-to-normal vision were divided into four groups (each $\mathrm{n}=10$ ): three karate groups and one group without karate experiences. Group 1 contained young adults at the age of 18-35 years (27.4 \pm 4.7 years). Group 2 comprised middle-aged adults at the age of 36-60 years (49.1 \pm 6.4 years). Group 3 were seniors over the age of 60 years $(71.3$ \pm 5.9 years). The young karate athletes (group 1) had $14 \pm 8$ years of karate experience and at least four years of competition experience with a belt degree of 7st Kyu until 2nd Dan. The middle-aged karate athletes (group 2) had $11 \pm 7$ years of karate experiences, but only half of them had competition experiences with a belt degree ranging from 8th Kyu until 3rd Dan. The senior karate athletes (group 3) had $6 \pm 3$ years of karate experience and none of them had competition experience with a belt degree of white belt until 3rd Kyu. Group 4 served as an age-matched group for group 1 and consisted of ten non-karate athletes with an age of $18-35$ years $(26.4$ \pm 3.5 years).

\subsubsection{Procedure}

In a seated position, the participants watched the VR app (karate movements of a virtual character) self-reliantly wearing the HMD for ten minutes (Fig.1) and then answered the SSQ verbally. 
Afterwards, they repeated the same test procedure but with slightly different app content (further karate movements of a virtual character) to make sure that the participants were not bored.

\subsubsection{Data analysis}

We analyzed 80 data sets (two per participant). We compared the groups 1-3 for the factor "age" and group 1 and 4 for the factor "familiarity with the content / expertise". The SSQs were analyzed according to the official guidelines ${ }^{[28]}$ and total scores were calculated. Analyses of variance (ANOVAs) were performed with "total score" as the depending variable, "age (18-35 years, 36-60 years, over 60 years)" and "familiarity with the content / expertise (karate experience versus no karate experience" as the between-subject variables, and "exposure time $(10$ minutes versus 20 minutes)" as the within-subject variable (repetition of measurement). Furthermore, we performed Bonferroni post-hoc-tests, as well as paired t-tests for differences within each group (10 versus 20 minutes) and unpaired t-tests for between-group differences. Effect sizes for significant results in the t-tests were examined using Pearson's correlation coefficient being defined as $\mathrm{r}=0.1$ small effect, $\mathrm{r}=0.3$ moderate effect, and $\mathrm{r}=0.5$ large effect. All analyses were conducted in SPSS (version 25, IBM, Germany) with a significance level of $\alpha=0.05$.

\subsection{Study 2}

In study 2 , we aimed to analyze the influence of gender and exposure time in VR on cybersickness. Therefore, we compared men with women using biofeedback measurements. Instead of applying the SSQ, we asked the participants to assess their physical comfort on a 10-point scale every five minutes and the participants gave verbal feedback (verbal reports).

\subsubsection{Participants}

Thirty healthy young adults (15 men and 15 women, age: $21.33 \pm 2.25$ years) with normal or corrected-to-normal vision and no previous karate expertise participated on voluntary basis.

\subsubsection{Procedure}

Similar to study 1, all participants watched the karate movements in the VR app in a seated position for a total of 20 minutes. We analyzed the cybersickness using the biofeedback system Biograph Infinity (MediTech, Germany), which provides the measurement of the heart rate and the skin conductance (Fig. 1). Furthermore, we obtained the subjective estimation of cybersickness by asking the participants to rate their physical comfort verbally on a scale from 1 point (no symptoms) to 10 points (severe problems with cybersickness). We obtained all baseline values prior to the exposure to VR, and then every five minutes until the end of the exposure to VR (after 5, 10, 15 and 20 minutes). In order to analyze recovery of potential symptoms, we also obtained data five and ten minutes after the completion of the exposure to VR (after 25, 30 minutes). To examine the heart rate and the skin conductance according to the official guidelines (Biograph Infinity, Meditech, Germany), we averaged all measured values ten seconds before and after every time point. The selection of these parameters was based on previous studies ${ }^{[1,30,31]}$. It was already highlighted that skin conductance is a useful parameter for the indication of cybersickness ${ }^{[41]}$. The presence of cybersickness can be expected in case of an increase in heart rate and skin conductance.

\subsubsection{Data analysis}

We analyzed 30 datasets at each time, thus 210 datasets. No dropout occurred. As relevant parameters, we analyzed the heart rate, skin conductance and the subjective estimation of cybersickness (verbal reports).

Normal distribution and variance homogeneity was only given for the parameter "heart rate". Therefore, time effects ("exposure time") for the parameter "heart rate" within each gender were examined using analyses of variance (ANOVA).

For the parameters "skin conductance" and "subjective estimation of cybersickness", we applied the Friedman-Tests with Dunn-Bonferronipost-hoc tests to analyze the effects of "exposure time (baseline, VR exposure after 5,10, 15, 20 minutes, recovery after 5 and 10 minutes after completion of VR)" for men and women separately. We used Pearson's correlation coefficient for the detection of effect sizes being defined as $\mathrm{r}=0.1$ small effect, $r=0.3$ moderate effect and $r=0.5$ large effect. 
Furthermore, we analyzed differences between men and women at each time point using unpaired t-tests for the parameter "heart rate" and KruskalWallis-tests for the parameters "skin conductance" and "subjective estimation of cybersickness". In case of significant differences, effect sizes using Pearson's correlation coefficient were calculated. All statistical tests were performed with SPSS (version 25, IBM, Germany) and a level of significance of $a=0.05$.

\section{Results}

\subsection{Study 1}

The total scores for each group are given in Table 1. The ANOVAs showed a significant effect for "exposure time" with $\mathrm{F}(1 / 9)=5.729, \mathrm{p}=0.022$, эp2 $=0.141$ (large effect). However, no significant interaction was found for "exposure time $\mathrm{x}$ group" with $\mathrm{F}(2 / 9)=0.932, \mathrm{p}>0.05$, for "exposure time $\mathrm{x}$ expertise" with $F(2 / 9)=0.002, p>0.05$, and for "exposure time $\mathrm{x}$ group $\mathrm{x}$ expertise" with $\mathrm{F}(5 / 9)=0.01, \quad \mathrm{p}>0.05)$. Bonferroni-post-hoc-tests showed a significant difference between group 1 (karate athletes 18-35 years) and group 4 (non karate athletes $18-35$ years) with $p=0.032$. The other group differences did not reach the level of significance $(\mathrm{p}>0.05)$.

The paired-t-tests confirmed the findings of the ANOVA and showed a significant difference between 10 and 20 minutes for group $3(p=0.045)$. The other paired t-tests showed no significant differences for the factor "exposure time" within the groups (all $\mathrm{p}>0.05$, see Tab. 1).

The unpaired t-tests for examining group differences for each exposure time only revealed a significant difference between group 2 and group 3 (10 minutes and 20 minutes, $\mathrm{p}<0.05$ ). For the factor "familiarity with the content / expertise", a significant difference was found between group 1 and group 4 for 20 minutes $(p=0.016)$, but not for 10 minutes $(p>0.05)$. Further details can be seen in Table 2.

The total scores found in study 1 can be classified as negligible and small for karate athletes of all ages (18 years up to over 60 years). These findings are in line with previous studies, in which no problems with cybersickness occurred either (e.g.
$[2,36])$. We only found a significant increase of cybersickness due to increasing the duration time in VR for karate athletes over 60 years, but not for the other age groups, which contradicts previous findings ${ }^{[29]}$ (see Tab.1). In all karate groups, the total scores of the SSQ for all karate groups varied between 4 and 11 points, thus were only small, but the standard deviations were quite high in all groups. In every group, the majority of the participants did not suffer from symptoms of cybersickness, but a few (2-4 athletes per groups) had several symptoms. Most often, these symptoms were induced by problems with oculomotor processes and disorientation. Thus, the occurrence of cybersickness seems to be an individual and hard to predictable process ${ }^{[13]}$.

\subsection{Study 2}

The results with means and standard deviations for each parameter, as well as gender differences and time effects within each group are shown in Table 3. We did not find any significant differences over time or between men and women for the parameter "heart rate" (all $\mathrm{p}>0.05$ ). With 60-90 beats per minutes, heart rates were normal and did not show any changes.

However, we found a similar and significant increase in the parameter "skin conductance" from $1 \mu \mathrm{S}$ (baseline) to $8 \mu \mathrm{S}$ at the end of the study (20 minutes VR plus 10 minutes rest) for both genders but no differences between men and women. We found significant time effects from baseline until 15, 20,25 and 30 minutes in women, and between baseline and 20, 25 and 30 minutes in men, indicating that changes in skin conductance occurred a little bit later in men.

For the parameter "subjective estimation of cybersickness" (scale from 1 point: no problems to 10 points: severe problems), we did not find any significant changes over time in men (almost no problems occurred at all time points). However, we found significant differences over time in women, especially between baseline and all other times. Although the women stated that they had more problems with cybersickness -and significant gender differences with large effects were found -, the values were still low and moderate (only around 2-4 points from the maximum of 10 points). 
Table 1: Results of the total scores of the SSQ and the effects of exposure time (10 minutes versus 20 minutes) within each group using paired t-tests. Significant differences are marked in bold

\begin{tabular}{|l|l|l|l|}
\hline group (each $\mathrm{n}=10)$ & $\begin{array}{l}\text { total scores of the SSQ } \\
\text { after 10 minutes } \\
\text { (mean } \pm \text { standard } \\
\text { deviation) }\end{array}$ & $\begin{array}{l}\text { total scores of the SSQ } \\
\text { after 20 minutes } \\
\text { (mean } \pm \text { standard } \\
\text { deviation) }\end{array}$ & $\begin{array}{l}\text { significance and effect sizes } \\
\text { using paired t-test and Pearson's r } \\
(10 \text { minutes versus 20 minutes per } \\
\text { group) }\end{array}$ \\
\hline $\begin{array}{l}\text { group 1: } \\
\text { karate athletes 18-35 } \\
\text { years }\end{array}$ & $6.23 \pm 8.57$ & $10.1 \pm 12.09$ & $\begin{array}{l}\mathrm{T}(9)=0.555, \\
\mathrm{p}=0.594\end{array}$ \\
\hline $\begin{array}{l}\text { group 2: } \\
\text { karate athletes 36-60 } \\
\text { years }\end{array}$ & $4.11 \pm 8.35$ & $6.73 \pm 11.53$ & $\begin{array}{l}\mathrm{T}(9)=1.769, \\
\mathrm{p}=0.111\end{array}$ \\
\hline $\begin{array}{l}\text { group 3: } \\
\text { karate athletes over } \\
\text { 60 years }\end{array}$ & $5.24 \pm 7.73$ & $7.85 \pm 10.79$ & $\begin{array}{l}\mathrm{T}(9)=-2.333, \\
\mathbf{p}=\mathbf{0 . 0 4 5}, \mathbf{r}=\mathbf{0 . 6 1} \text { (large effect) }\end{array}$ \\
\hline $\begin{array}{l}\text { group 4: } \\
\text { non karate athletes } \\
\text { 18-35 years }\end{array}$ & $18.7 \pm 15.87$ & $28.8 \pm 26.27$ & $\begin{array}{l}\mathrm{T}(9)=-2.050, \\
\mathrm{p}=0.071\end{array}$ \\
\hline
\end{tabular}

Table 2: Results of the group differences using unpaired t-tests. Group 1: karatekas 18-35 years. Groups 2: karatekas 36-60 years. Group 3: karatekas over 60 years. Group 4: non-karatekas 18-35 years. Significant differences are marked in bold

\begin{tabular}{|c|c|c|}
\hline factor & $\begin{array}{l}\text { group differences (each group } \\
n=10)\end{array}$ & $\begin{array}{l}\text { significance and effect sizes using paired } \\
\text { t-test and Pearson's } r\end{array}$ \\
\hline \multirow[t]{2}{*}{$\begin{array}{l}\text { familiarity with the content } \\
\text { / expertise }\end{array}$} & $\begin{array}{l}\text { group } 1 \text { versus group } 4-10 \\
\text { minutes }\end{array}$ & $\mathrm{T}(18)=-1.363, \mathrm{p}=0.190$ \\
\hline & $\begin{array}{l}\text { group } 1 \text { versus group } 4-20 \\
\text { minutes }\end{array}$ & $\begin{array}{l}\mathrm{T}(18)=-1.363, \mathbf{p}=\mathbf{0 . 0 1 6}, \mathbf{r}=\mathbf{0 . 3 0} \\
\text { (moderate effect) }\end{array}$ \\
\hline \multirow[t]{6}{*}{ age } & $\begin{array}{l}\text { group } 1 \text { versus group } 2-10 \\
\text { minutes }\end{array}$ & $\mathrm{T}(18)=0.637, \mathrm{p}=0.532$ \\
\hline & $\begin{array}{l}\text { group } 1 \text { versus group } 2-20 \\
\text { minutes }\end{array}$ & $\mathrm{T}(18)=0.401, \mathrm{p}=0.693$ \\
\hline & $\begin{array}{l}\text { group } 1 \text { versus group } 3-10 \\
\text { minutes }\end{array}$ & $\mathrm{T}(18)=1.071, \mathrm{p}=0.298$ \\
\hline & $\begin{array}{l}\text { group } 1 \text { versus group } 3-20 \\
\text { minutes }\end{array}$ & $\mathrm{T}(18)=-0.521, \mathrm{p}=0.609$ \\
\hline & $\begin{array}{l}\text { group } 2 \text { versus group } 3-10 \\
\text { minutes }\end{array}$ & $\begin{array}{l}\mathrm{T}(18)=-2.572, \mathbf{p}=\mathbf{0 . 0 1 9}, \mathbf{r}=\mathbf{0 . 5 2} \text { (large } \\
\text { effect) }\end{array}$ \\
\hline & $\begin{array}{l}\text { group } 2 \text { versus group } 3-20 \\
\text { minutes }\end{array}$ & $\begin{array}{l}T(18)=-2.721, p=0.014, r=0.55 \text { (large } \\
\text { effect) }\end{array}$ \\
\hline
\end{tabular}


Table 3: Results of the parameters "heart rate", "skin conductance" and "subjective estimation of cybersickness" in mean \pm SD for each time and gender. Effects of exposure time for each group were examined using ANOVA and Friedman Tests. Gender comparisons at each time were performed using unpaired t-tests or Kruskal-Wallis tests and estimation of effect sizes (Person's correlation coefficient, $r$ ). Significant differences are marked in bold

\begin{tabular}{|c|c|c|c|c|c|c|c|c|c|}
\hline \multicolumn{10}{|c|}{ heart rate (beats per minutes) } \\
\hline & \multicolumn{9}{|c|}{ time } \\
\hline group & $\begin{array}{l}\text { baseline } \\
\text { (no VR) }\end{array}$ & $\begin{array}{l}\text { VR } \\
\text { after } 5 \\
\text { minutes }\end{array}$ & $\begin{array}{l}\text { VR } \\
\text { after } 10 \\
\text { minutes }\end{array}$ & $\begin{array}{l}\text { VR } \\
\text { after } 15 \\
\text { minutes }\end{array}$ & $\begin{array}{l}\text { VR } \\
\text { after } 20 \\
\text { minutes }\end{array}$ & $\begin{array}{l}5 \\
\text { minutes } \\
\text { after } \\
\text { VR } \\
(25 \\
\text { min) }\end{array}$ & $\begin{array}{l}10 \text { minutes } \\
\text { after VR } \\
(30 \text { min) }\end{array}$ & $\begin{array}{l}\text { significance } \\
\text { of exposure } \\
\text { time }\end{array}$ & $\begin{array}{l}\text { significan } \\
\text { t post- } \\
\text { hoc-tests } \\
\text { and } \\
\text { effect } \\
\text { sizes }\end{array}$ \\
\hline men & $\begin{array}{l}81.92 \pm \\
10.42\end{array}$ & $\begin{array}{l}79.54 \pm \\
9.66\end{array}$ & $\begin{array}{l}78.75 \pm \\
9.81\end{array}$ & $\begin{array}{l}78.09 \pm \\
9.73\end{array}$ & $\begin{array}{l}78.17 \pm \\
9.60\end{array}$ & $\begin{array}{l}78.47 \pm \\
9.44\end{array}$ & $\begin{array}{l}78.95 \pm \\
9.42\end{array}$ & $\begin{array}{l}F(6 / 98)=0.27 \\
9, \\
p=0.946\end{array}$ & -- \\
\hline women & $\begin{array}{l}83.55 \pm \\
8.53\end{array}$ & $\begin{array}{l}80.10 \pm \\
7.09\end{array}$ & $\begin{array}{l}80.50 \pm \\
7.02\end{array}$ & $\begin{array}{l}79.71 \pm \\
6.90\end{array}$ & $\begin{array}{l}79.51 \pm \\
6.68\end{array}$ & $\begin{array}{l}79.84 \pm \\
6.37\end{array}$ & $\begin{array}{l}80.15 \pm \\
6.14\end{array}$ & $\begin{array}{l}F(6 / 98)=0.59 \\
3 \\
p=0.735\end{array}$ & -- \\
\hline $\begin{array}{l}\text { group } \\
\text { com- } \\
\text { parison } \\
\text { using t- } \\
\text { tests }\end{array}$ & $\begin{array}{l}\mathrm{T}(28)=- \\
0.469 \\
\mathrm{p}=0.643\end{array}$ & $\begin{array}{l}\mathrm{T}(28)=- \\
0.469 \\
\mathrm{p}=0.642\end{array}$ & $\begin{array}{l}T(28)=- \\
0.560 \\
p=0.580\end{array}$ & $\begin{array}{l}\mathrm{T}(28),=- \\
0.528, \\
\mathrm{p}=0.602\end{array}$ & $\begin{array}{l}\mathrm{T}(28)=- \\
0.442, \\
\mathrm{p}=0.662\end{array}$ & $\begin{array}{l}\mathrm{T}(28)=- \\
0.468, \\
\mathrm{p}=0.643\end{array}$ & $\begin{array}{l}T(28)=0.41 \\
6, \\
p=0.681\end{array}$ & & \\
\hline \multicolumn{10}{|c|}{ skin conductance $(\mu \mathrm{S})$} \\
\hline & \multicolumn{9}{|c|}{ time } \\
\hline group & $\begin{array}{l}\text { baseline } \\
\text { (no VR) }\end{array}$ & $\begin{array}{l}\text { VR } \\
\text { after } 5 \\
\text { minutes }\end{array}$ & $\begin{array}{l}\text { VR } \\
\text { after } 10 \\
\text { minutes }\end{array}$ & $\begin{array}{l}\text { VR } \\
\text { after } 15 \\
\text { minutes }\end{array}$ & $\begin{array}{l}\text { VR } \\
\text { after } 20 \\
\text { minutes }\end{array}$ & $\begin{array}{l}5 \\
\text { minutes } \\
\text { after } \\
\text { VR (25 } \\
\text { min) }\end{array}$ & $\begin{array}{l}10 \text { minutes } \\
\text { after VR } \\
(30 \text { min })\end{array}$ & $\begin{array}{l}\text { significance } \\
\text { of exposure } \\
\text { time }\end{array}$ & $\begin{array}{l}\text { significan } \\
\text { t post- } \\
\text { hoc-tests } \\
\text { and } \\
\text { effect } \\
\text { sizes } \\
\text { (Pearson' } \\
\text { S r) } \\
\end{array}$ \\
\hline men & $\begin{array}{l}2.93 \pm \\
2.02\end{array}$ & $\begin{array}{l}3.90 \pm \\
2.77\end{array}$ & $\begin{array}{l}4.44 \pm \\
2.96\end{array}$ & $\begin{array}{l}4.57 \pm \\
3.01\end{array}$ & $\begin{array}{l}5.23 \pm \\
3.60\end{array}$ & $\begin{array}{l}5.74 \pm \\
3.25\end{array}$ & $6.17 \pm 3.62$ & $\begin{array}{l}\chi^{2}(6)=66.343, \\
\mathbf{p}<\mathbf{0 . 0 0 1}\end{array}$ & $\begin{array}{l}\text { see Note } \\
1^{*} \text { below } \\
\text { this table }\end{array}$ \\
\hline women & $\begin{array}{l}2.33 \pm \\
1.14\end{array}$ & $\begin{array}{l}3.11 \pm \\
1.53\end{array}$ & $\begin{array}{l}3.76 \pm \\
2.08\end{array}$ & $\begin{array}{l}3.48 \pm \\
1.75\end{array}$ & $\begin{array}{l}3.84 \pm \\
2.24\end{array}$ & $\begin{array}{l}4.79 \pm \\
2.34\end{array}$ & $4.82 \pm 2.48$ & $\begin{array}{l}\chi^{2}(6)=59.234 \\
\mathbf{p}<\mathbf{0 . 0 0 1}\end{array}$ & $\begin{array}{l}\text { see Note } \\
2^{*} \text { below } \\
\text { this table }\end{array}$ \\
\hline
\end{tabular}




\begin{tabular}{|c|c|c|c|c|c|c|c|c|c|}
\hline $\begin{array}{l}\text { group } \\
\text { com- } \\
\text { parison } \\
\text { using } \\
\text { Kruskal } \\
\text {-Wallis } \\
\text { tests }\end{array}$ & $\begin{array}{l}\mathrm{H}=0.97 \\
0, \\
p=0.765\end{array}$ & $\begin{array}{l}\mathrm{H}=0.20 \\
8 \\
\mathrm{p}=0.648\end{array}$ & $\begin{array}{l}\mathrm{H}=0.36 \\
2, \\
\mathrm{p}=0.548\end{array}$ & $\begin{array}{l}\mathrm{H}=0.72 \\
3 \\
\mathrm{p}=0.395\end{array}$ & $\begin{array}{l}H=0.65 \\
4 \\
p=0.419\end{array}$ & $\begin{array}{l}\mathrm{H}=0.41 \\
3, \\
\mathrm{p}=0.520\end{array}$ & $\begin{array}{l}\mathrm{H}=1.033, \\
\mathrm{p}=0.310\end{array}$ & & \\
\hline \multicolumn{10}{|c|}{ estimation of cybersickness (scale from 1 point (no problems) to 10 points (severe problems)) } \\
\hline & \multicolumn{9}{|c|}{ time } \\
\hline group & $\begin{array}{l}\text { baseline } \\
\text { (no VR) }\end{array}$ & $\begin{array}{l}\text { VR } \\
\text { after } 5 \\
\text { minutes }\end{array}$ & $\begin{array}{l}\text { VR } \\
\text { after } 10 \\
\text { minutes }\end{array}$ & $\begin{array}{l}\text { VR } \\
\text { after } 15 \\
\text { minutes }\end{array}$ & $\begin{array}{l}\text { VR } \\
\text { after } 20 \\
\text { minutes }\end{array}$ & $\begin{array}{l}5 \\
\text { minutes } \\
\text { after } \\
\text { VR }(25 \\
\text { min) }\end{array}$ & $\begin{array}{l}10 \text { minutes } \\
\text { after } V R \\
(30 \text { min })\end{array}$ & $\begin{array}{l}\text { significance } \\
\text { of exposure } \\
\text { time }\end{array}$ & $\begin{array}{l}\text { significan } \\
\text { t post- } \\
\text { hoc-tests } \\
\text { and } \\
\text { effect } \\
\text { sizes } \\
\text { (Pearson' } \\
\text { s r) }\end{array}$ \\
\hline men & $\begin{array}{l}0.13 \pm \\
0.51\end{array}$ & $\begin{array}{l}0.2 \pm \\
0.56\end{array}$ & $\begin{array}{l}0.33 \pm \\
0.62\end{array}$ & $\begin{array}{l}0.27 \pm \\
0.60\end{array}$ & $\begin{array}{l}0.2 \pm \\
0.56\end{array}$ & $\begin{array}{l}0.2 \pm \\
0.56\end{array}$ & $0.2 \pm 0.56$ & $\begin{array}{l}\chi^{2}(6)=10.364 \\
p=0.110\end{array}$ & -- \\
\hline women & $\begin{array}{l}0.17 \\
\pm 0.35\end{array}$ & $\begin{array}{l}1.1 \pm \\
1.39\end{array}$ & $\begin{array}{l}1.68 \pm \\
1.58\end{array}$ & $\begin{array}{l}1.91 \pm \\
1.79\end{array}$ & $\begin{array}{l}1.87 \pm \\
2.10\end{array}$ & $\begin{array}{l}1.41 \pm \\
1.71\end{array}$ & $0.94 \pm 1.1$ & $\begin{array}{l}\chi^{2}(6)=23.501 \\
\mathbf{p}=\mathbf{0 . 0 0 1}\end{array}$ & $\begin{array}{l}\text { see Note } \\
3{ }^{*} \text { below } \\
\text { this table }\end{array}$ \\
\hline $\begin{array}{l}\text { group } \\
\text { com- } \\
\text { parison } \\
\text { using } \\
\text { Kruskal } \\
\text {-Wallis } \\
\text { tests }\end{array}$ & $\begin{array}{l}\mathrm{H}=2.07 \\
1, \\
\mathrm{p}=0.150\end{array}$ & $\begin{array}{l}\mathrm{H}=5.14 \\
4, \\
\mathbf{p}=\mathbf{0 . 0 2 3} \\
\mathbf{r}=\mathbf{0 . 9 3 9} \\
\text { (large } \\
\text { effect) }\end{array}$ & $\begin{array}{l}\mathrm{H}=5.67 \\
5, \\
\mathbf{p}=\mathbf{0 . 0 1 7} \\
, \\
\mathbf{r}=\mathbf{1 . 0 3 1} \\
\text { (large } \\
\text { effect) }\end{array}$ & $\begin{array}{l}\mathrm{H}=8.46 \\
2, \\
\mathbf{p}=\mathbf{0 . 0 0 4} \\
, \\
\mathbf{r}=\mathbf{1 , 5 4 5} \\
\text { (large } \\
\text { effect) }\end{array}$ & $\begin{array}{l}\mathrm{H}=6.68 \\
3, \\
\mathbf{p}=\mathbf{0 . 0 1 0} \\
, \\
\mathbf{r}=\mathbf{1 . 2 2 0} \\
\text { (large } \\
\text { effect) }\end{array}$ & $\begin{array}{l}\mathrm{H}=6.57 \\
0, \\
\mathbf{p}=\mathbf{0 . 0 1 0} \\
, \\
\mathbf{r}=\mathbf{1 . 2 0 0} \\
\text { (large } \\
\text { effect) }\end{array}$ & $\begin{array}{l}\mathrm{H}=4.895, \\
\mathbf{p}=\mathbf{0 . 0 2 7}, \\
\mathbf{r}=\mathbf{0 . 8 9 4} \\
\text { (large } \\
\text { effect) }\end{array}$ & & \\
\hline
\end{tabular}

\section{*Note 1:}

0-20 min: $\mathrm{p}<0.001, \mathrm{r}=0.963$ (large effect) $0-25$ min: $p<0.001, r=1.188$ (large effect) 0-30 min: $p<0.001, r=1.240$ (large effect) 5-20 min: $\mathrm{p}=0.004, \mathrm{r}=0.757$ (large effect) 5-25 min: $\mathrm{p}<0.001, \mathrm{r}=0.981$ (large effect) 5-30 min: $p<0.001, r=1.033$ (large effect) 10-25 min: $\mathrm{p}=0.015, \mathrm{r}=0.689$ (large effect) 10-30 min: $p=0.006, r=0.740$ (large effect) 15-30 min: $p=0.037, r=0.640$ (large effect)

\section{${ }^{*}$ Note 2:}

$0-15$ min: $\mathrm{p}=0.028, \mathrm{r}=0.654$ (large effect) 0-20 min: $\mathrm{p}=0.008, \mathrm{r}=0.723$ (large effect) 0-25 min: $\mathrm{p}<0.001, \mathrm{r}=1.231$ (large effect) 0-30 min: $p<0.001, r=1.274$ (large effect) 5-25 min: $\mathrm{p}<0.001, \mathrm{r}=0.895$ (large effect) 5-30 min: $\mathrm{p}=0.001, \mathrm{r}=0.852$ (large effect) 10-25 min: $\mathrm{p}=0.010, \mathrm{r}=0.714$ (large effect) 10-30 min: $\mathrm{p}=0.021, \mathrm{r}=0.671$ (large effect) 15-25 min: $\mathrm{p}=0.049, \mathrm{r}=0.620$ (large effect)

\section{*Note 3:}

0-5 min: $\mathrm{p}=0.027, \mathrm{r}=0.572$ (large effect) $0-10$ min: $p=0.010, r=0.667$ (large effect) $0-15$ min: $p=0.009, r=0.671$ (large effect) $0-20$ min: $p=0.016, r=0.620$ (large effect) $0-25$ min: $\mathrm{p}=0.017, \mathrm{r}=0.620$ (large effect) 10-30 min: $\mathrm{p}=0.026, \mathrm{r}=0.573$ (large effect) 15-30 min: $\mathrm{p}=0.015, \mathrm{r}=0.631$ (large effect) 25-30 min: $\mathrm{p}=0.038, \mathrm{r}=0.534$ (large effect) 


\section{Discussion}

There is still inconsistency in the literature regarding the incidence of cybersickness. While older studies (e.g. ${ }^{[1,29]}$ ) showed that cybersickness occurred in $80 \%$ of all cases when using HMDs, [22, 36] did not report any symptoms of cybersickness. Thus, the technological progress might help to reduce symptoms due to a decrease in delays, higher resolution and a larger field of view. [20] observed that athletes preferred CAVEs over HMDs, but ${ }^{[22]}$ showed the opposite: karate athletes preferred the HMD compared to a CAVE because of the much larger freedom of movements and the small weight of the HMD. The degree of realism was higher in an HMD because the athletes were completely surrounded by the virtual environment. Therefore, we also chose an HMD and a third person perspective as recommended previously ${ }^{[42]}$.

We extended a previous study ${ }^{[2]}$ by increasing the duration time in VR and found significant effects for "familiarity of the shown content / expertise" (here the sports karate) and "age" (study 1 ), as well as for "gender" (study 2), and for exposure time" (both studies) on cybersickness when using the VR app.

In study 1, the factors "age" "and exposure" time had an effect on cybersickness. Although there were no differences between 10 minutes and 20 minutes duration in VR for karatekas from 18 until 60 years, a significant difference was observed for the adults over 60 years. In that age group (over 60 years), the symptoms increased significantly and with large effects from ten minutes to 20 minutes of exposure time to VR. However, adults in that group had the lowest total scores for exposure times of ten minutes. Some symptoms of cybersickness occurred in the first 10 minutes in all measured groups and remained quite stable (and well bearable) in the next 10 minutes. Furthermore, we observed a significant difference between young karate athletes (group 1) and the age matched non-karate athletes (group 4) for the duration of 20 minutes but not 10 minutes (Tab.2). The total scores of the SSQ for the nonkarate athletes were extremely high and can be classified as major problem, but also the standard deviations were very high. From the 10 participants, 3 did not show any problems at all, but the remaining 7 had small problems with all symptoms.
We assume that not being familiar with the sports specific content shown in VR may promote the occurrence of cybersickness. Thus, for sports specific scenarios, we would recommend to show the content that the participants are used to, especially for VR session lengths over ten minutes. Based on our results, we need to reject our assumption that the factors "familiarity with the content" and "age" do not have an influence on cybersickness. However, as expected, the " exposure time" had an effect on cybersickness in senior karatekas and participants not being familiar with the content presented (here a karate kumite attack). We need to mention, that although we found some significant differences between groups and over time, all detected symptoms were only moderate or low according to the guidelines ${ }^{[28]}$.

In study 2, we did not find any significant effects for the parameter "heart rate", but significant time effects in "skin conductance" for both men and women. However, no gender differences in skin conductance were observed. The increase of skin conductance was similar in men and women. However, based on ${ }^{[31]}$, skin conductance might be increased due to the VR environment itself inducing a stressful situation or on the other hand due to the concentration on the task. Therefore, we cannot be sure that we have measured cybersickness because the men stated to not have problems with cybersickness (verbal reports). Although ${ }^{[41]}$ found a correlation between skin conductance and cybersickness, it is possible that we have measured arousal rather than cybersickness. Therefore, we conclude that heart rate and skin conductance are not sensitive enough and thus not suitable to detect cybersickness. Questionnaires or verbal reports as used in this study seem to be more appropriate. We also found significant time effects in the estimation of cybersickness (verbal reports) for women, but not for men indicating that gender differences perceiving cybersickness exist. However, only half of the tested women had greater problems while the other half had no problems at all. Thus, in women, the occurrence of cybersickness seems to be more individual compared to men. Female participants showed greater symptoms than men, as it was reported previously (e.g. [26]), but these were also generally moderate and only in few cases quite high. Furthermore, it was found that women were also 
able to recover quite fast (Tab. 3), which is in line with $[13,26,43]$. After 10 minutes recovery, the parameters were almost at the same level as after five minutes in VR. It is assumed that after 15 minutes recovery, the parameters were could have reached baseline values. Thus, we need to reject our assumption that no gender differences would occur, but as expected, we found several time effects. While ${ }^{[2]}$ did not find any gender effects, perhaps due to technological progress, we detected significant differences between men and women at all time points except for the baseline. In the mentioned study ${ }^{[2]}$, it was further demonstrated that women feel VR more real compared to men. Our results are not in line with these findings. In the current study, women had more problems with cybersickness although the level was moderate and no dropout occurred as it was shown in previous studies (e.g. ${ }^{[36]}$ ). About half of our female participants was affected by travel sickness, which could have influenced our results ${ }^{[44]}$. Therefore, it would be interesting to repeat our study and compare women with known travel sickness with women with no problems of travel sickness.

Based on our results, VR session lengths of 10 minutes seem to be appropriate for both genders, all ages (18 years until over 60 years) regardless of the fact that the participants are familiar with the sportsspecific content shown in VR. However, at exposure times of 20 minutes, participants, who were not familiar with the sports and seniors over the age of 60 years, suffered from more symptoms of cybersickness although these were only moderate and low. For young and healthy men, VR session lengths of around 20 minutes seem to be bearable, while women showed more symptoms of cybersickness in general. Thus, VR session lengths for women should not exceed 10 minutes. Longer session lengths should only be provided according to individual estimation.

Possible solution approaches to reduce cybersickness would be a slow increase of duration time in VR, individual breaks, the implementation of additional objects or characters for better orientation, as well as further feedback, such as haptics or acoustics ${ }^{[12,13]}$. Another idea is to stimulate the vestibular system invasively with galvanic instruments [45], but that is not quite practical in sports applications. According to [31], also breathing techniques can be used to maintain physical comfort and thus avoid cybersickness. Furthermore, the integration of a virtual body or a body part, e.g. the nose, can help for a better orientation ${ }^{[10,46]}$. Moreover, feedback could be given to ensure more motivation and better outcome [47,48]. In general, developers should ensure high frame rates and low (HMD) latencies what was also the case in the present experiments.

Limitations and future directions

Nevertheless, we need to mention some limitations of the current study. We had a small sample size with only 10-15 participants in each tested group. We are still not able to identify conclusively the relevant factors leading to cybersickness. Based on our results, all analyzed factors (age, familiarity with shown content, gender and exposure time) had a significant effect on the physical comfort during the stay in VR.

Although no delays are occurring in the current VR app as already recommended [9, 10,13, 23], the VR app should be improved on the technical level to enhance the resolution. Furthermore, the virtual character should be visualized as a karateka and further karate techniques and information should be provided to allow future studies with even longer exposure times.

Last but not least, we only analyzed the occurrence of cybersickness in a seated position. However, it would be interesting to examine cybersickness in conditions where natural body movements are allowed [13, 19,27]. In future studies with the VR app, it could be possible to let the participants watch the karate content and let them imitate the observed karate movements immediately afterwards. Cybersickness could then be analyzed with questionnaires or verbal reports. Sitting still was a problem in the current studies as only head movements were allowed, especially in study 2 to avoid interfering with the biofeedback measurement. Many participants, especially men, wanted to imitate the karate movements during the observation. That result is in line with the study, in which the same VR app was already used to enhance own movement executions by observational learning ${ }^{[35]}$. We conclude that, although some improvements should be made on the technical level, the VR app seems to be animating. 


\section{Conclusion}

VR training can then be carried out either physically (e.g. ${ }^{[32,33]}$ ), or due to observational learning as it was performed in ${ }^{[35]}$. As training in real world, such VR training might lead to better performance and can prevent body dysfunctions (e.g. ${ }^{[49]}$ ).

Although the observer cannot perform own sports specific movements, the VR app can be very useful for additional training alone at home or wherever wireless internet is available. The app is for free and easy to use. Such observational learning can be used for deepening the knowledge about correct movement execution, improving own motor execution and for increasing the motivation because it is a new training tool. However, we recommend to use the VR app in a safe and calm environment and to stop the application immediately in case of any symptoms of discomfort.

We conclude that VR applications and interventions-at least when participants are seated in VR without additional movement executions - can be used for healthy adult athletes of all ages (18 until over 60 years) for a duration of at least 10 minutes. For adults at the age of 18-60 years, and especially healthy male participants who are already familiar with the VR content, exposure times of 20 minutes are possible. However, for women and seniors over 60 years or persons, which are not familiar with the sports-specific content (the shown sports), sessions should not exceed 10 minutes. These results can be used to provide more flexibility in creating VR training. All detected symptoms of cybersickness were only low or moderate. 10 minutes of exposure time are appropriate for VR session lengths; longer exposure times of up to 20 minutes should be tested carefully and individually.

\section{Acknowledgements}

The current work was supported by the German Research Foundation (DFG) under grant WI 1456/17-22-1. We thank Dr. Peter Emmermacher, Christian Timmerevers, Noah Müller and the Fraunhofer Institute for Factory Operation and Automation IFF in Germany for support in the creation of the VR app content. We further thank Prof. Dr. Claus-Dieter Ohl for his support and the contact to Binoo (www.edu2vr.com) providing the freebie VR app and the server. Moreover, we thank Stefanie John for proofreading.

\section{Declaration of Interest}

The authors disclose any financial arrangement with a corporate whose product or with a company making a competitive product. They disclose all financial and personal relationships that might bias or be seen to bias their work.

\section{References}

1 Bruck, S.; Watters, P.A. The factor structure of cybersickness. Displays, 2011, 32, 153-158. doi: $\underline{\text { 10.1016./j.displa.2011.07.002 }}$

2 Melo, M.; Vasconcelos-Raposo, J.; Bessa, M. Presence and cybersickness in immersive content: Effects of content type, exposure time and gender. Computer \& Graphics, 2018, 71, 159-165. doi: 10.1016/j.cag.2017.11.007

3 Abeba, B.; W, O. Develop an automatic CAD system for cancer detection and its a multi class classification system through density based clustering and deep neural network. American Journal of Business and Management Sciences, 2019.

4 Donkin, R.; Askew, E. An evaluation of formative "in-class" versus "E-Learning" activities to benefit student learning outcomes in biomedical sciences. Journal of Biomedical Education, 2017: $9127978 . \quad$ doi: $\underline{10.1155 / 2017 / 9127978}$

5 Akbas A, Marszalek W, Kamieniarz A, Polechonski J, Slomka KJ, Juras G. Application of Virtual Reality in Competitive Athletes - A Review. J Hum Kinet 2019; 69: 5-16 DOI: $10.2478 /$ hukin-2019-0023

6 Checa, D.; Bustillo, A. A review of immersive virtual reality serious games to enhance learning and training. Multimedia Tools and Applications, 2019, 1-27. doi: $\underline{10.1007 / \mathrm{s} 11042-019-08348-9}$

7 Michalski SC, Szpak A, Loetscher T. Using Virtual Environments to Improve Real-World Motor Skills in Sports: A Systematic Review. Front Psychol 2019; 10: 2159 DOI: 10.3389/fpsyg.2019.02159 
Petri,K.;Ohl,C.D.;Danneberg,M;Emmermacher, P.; Masik, S.; Witte, K. Towards the usage of virtual reality for training in sports. Biomedical Journal of Scientific \& Technical Research, 2018, 7(1), 1-3. doi: 10.26717/BJSTR.2018.07.001453

9 Petri, K.; Bandow, N.; Witte, K. Using several types of virtual characters in sports - a literature survey. International Journal of Computer Science in Sport, 2018, 17(1), 1-48, doi: $10.2478 /$ ijcss-2018-0001

10 Caserman P, Garcia-Agundez A, Goebel S. A Survey of Full-Body Motion Reconstruction in Immersive Virtual Reality Applications. IEEE Trans Vis Comput Graph 2019 DOI: 10.1109/TVCG.2019.2912607

11 Davis, S.; Nesbitt, K.; Nalivaiko, E. A systematic review of cybersickness. IE Proceedings of the 2014 conference on Interactive Entertainment, 2014, 1-9. doi: $\underline{10.1145 / 2677758.2677780}$

12 LaViola, J.J.Jr. A discussion of Cybersickness in Virtual Environments. ACM SIGCHI Bulletin, 2000, 32(1), 47-56. doi: 10.1145/33329.333344

13 Rebenitsch, L.; Owen, C. Review on cybersickness in applications and visual displays. Virtual Reality, 2016, 20, 101-125. doi: $10.1007 / \mathrm{s} 10055-016-0285-9$

14 Weech S,Kenny S,Barnett-Cowan M.Presence and Cybersickness in Virtual Reality Are Negatively Related: A Review. Front Psychol 2019; 10: 158 DOI: 10.3389/fpsyg.2019.00158

15 Robert, M.T.; Ballaz, L.; Lemay, M. The effect of viewing a virtual environment through a head-mounted display on balance. Gait \& Posture, 2016, 48, 261-266. doi: 10.1016/j.gaitpost.2016.06.10

16 Abtahi, P.; Gonzalez-Franco, M.; Ofek, E.; Steed, A. I'm a Giant: Walking in large virtual environments at high speed gains. Proceedings of CHI Conference on Human Factors in Computing Systems (CHI '19, May 4-9, 2019, Glasgow, Scotland UK. ACM, New York, NY, USA, 2019, 13 pages. doi: $\underline{10.1145 / 3290605.3300752}$

17 Banos RM, Botella C, Alcaniz M, Liano V, Guerrero B, Rey B. Immersion and emotion: their impact on the sense of presence.
Cyberpsychol Behav 2004; 7(6): 734-741 DOI: 10.1089/cpb.2004.7.734

18 Sharples, S.; Cobb, S.; Moody, A.; Wilson, J.R. Virtual reality induced symptoms and effects (vrise): Comparison of head mounted display (hmd), desktop and projection display systems. Displays, 2008, 29(2), 58-69. doi: 10.1016/j.displa.2007.09.005

19 Fernandes, A.S.; Feiner, S.K. Combatting VR Sickness through Subtle Dynamic Field-OfView Modification.Proceedings of the IEEE Symposium on 3D User Interfaces, 2016. doi: 10.1109/3DUI.2016.7460053

20 Juan, M.C.; Pérez, D. Comparison of the levels of presence and anxiety in anacrophobic environment viewed via HMD or CAVE. Presence, 2009, 18(3), 232 - 248.

21 Komura, T.;Lau,R.W.H.; Lin, M.C.; Majumder, A.; Manocha, D.; Xu, W.W. Virtual reality Software and Technology. IEEE Computer Graphics and Applications, 2015, 20-21.

22 Petri, K.;Witte, K.;Bandow, N.;Emmermacher, P.; Masik, S.; Danneberg, M.; Salb, S.; Zhang, L.; Brunnett, G. Development of an autonomous character in karate kumite. Proceedings of the 11th International Symposium on Computer Science in Sport (IACSS 2017), Advances in Intelligent Systems and Computing, 2017, 663, 124-135. Springer International Publishing. doi: 10.1007/978-3-319-67846-1 13

23 Carnegie K, Rhee T. Reducing Visual Discomfort with HMDs Using Dynamic Depth of Field. IEEE Comput Graph Appl 2015; 35(5): 34-41 DOI: $10.1109 / \mathrm{MCG} .2015 .98$

24 Zielinski, D.J.;Rao, H.M.;Sommer, M.A.; Kopper, R. Exploring the Effects of Image Persistence in Low Frame Rate Virtual Environments.Proceedings of 2015 IEEE Virtual Reality (VR) Conference (Arles, Frankreich), IEEE, 2015, 19-26.

25 Lenggenhager $\mathrm{B}$, Lopez $\mathrm{C}$, Blanke O. Influence of galvanic vestibular stimulation on egocentric and object-based mental transformations. Exp Brain Res 2008; 184(2): 211-221 DOI: $10.1007 / \mathrm{s} 00221-007-1095-9$

26 Clemes, S.A;Howarth P.A.The menstrual cycle and susceptibility to virtual simulation sickness. 
Journal of Biological Rhythms, 2005, 20(1), $71-82$.

27 Katz, L.; Parker, J.; Tyreman, H.; Levy, R. (2008). Virtual reality. In: A. Baca \& P. Dabnichi (eds.), Computers in sport,Southampton: WIT. 2008, 3-41.

28 Kennedy, R.S.; Lane, N.E.; Berbaum, K.S.; Lilienthal, M.G. Simulator Sickness Questionnaire: An Enhanced Method for Quantifying Simulator Sickness. The International Journal of Aviation Psychology, 1993, 3(3), 203-220. doi: 10.1207/s15327108ijap03033

29 Moss, J.D.; Austin, J.; Salley, J.; Coats, J.; Williams, K.; Muth, E.R. The effects of display delay on simulator sickness. Displays, 2011, 32, 159-168. doi: 10.1016/j.displa.2011.05.010

30 Yokota, Y.; Aoki, M.; Mizuta, K.; Ito, Y.; Isu, $\mathrm{N}$. Motion sickness susceptibility associated with visually induced postural instability and cardiac autonomic responses in healthy subjects.Acta Oto-Laryngologica， 2005, 125(3), 280-285.

31 Dennison, M.S.;Wisti, A.Z.; D'Zmura, M. Use of physiological signals to predict cybersickness. Displays, 2016, 44, 42-52. doi: 10.1016/j.displa.2016.07.002

32 Petri, K.; Emmermacher, P.; Danneberg, M.; Masik, S.; Eckardt, F.; Weichelt, S.; Bandow, N.; Witte, K. Training using virtual reality improves response behavior in karate kumite. Sports Engineering, 2019, 22:2. doi: 10.1007/s12283-019-0299-0

33 Petri,K.;Masik,;Danneberg, M.;Emmermacher, P.; Witte, K. Possibilities to use a virtual opponent for enhancements of reactions and perception of young karate athletes. International Journal of Computer Science in Sport, 2019, 18(2) (Special Edition), 1-14. doi: 10.2478/ijcss-2019-0011

34 Cannavò, A.; Musto, M.; Pratticò, F.G.; Raho, F.; Lamberti, F. A participative system for tactics analysis in sport training based on immersive virtual reality. Proceeding of the 4th workshop on Everyday Virtual Reality (WEVR 2018) - 25th IEEE conference on
Virtual Reality and 3D User Interfaces, 2018, 1-4.

35 Petri, K.;Timmerevers, C.;Luxemburg, J.; Emmermacher, P.; Ohl, C.-D.; Danneberg, M.; Masik, S.; Witte, K. Improvement of movement execution in karate due to cognitive training with a virtual reality application for smartphones. Journal of Martial Arts Research, 2019, 2(1), 1-21. doi: 10.15495/ojs_25678221_21

36 Hartnagel,D.;Taffou,M.;Sandor,P.M.B. (2017). Effects of short exposure to a simulation in a head-mounted device and the individual difference issue. In: C. Stephanidis (ed.) HCI International 2017 - Posters' Extended Abstracts. HCI 2017. Communications in Computer and Information Science, 2017, 714. Springer, Cham. doi: 10.1007/978-3-31958753-0 2

37 Rose, F.D.;Attree, E.A.;Brooks, B.M.; Parslow, D.M.; Penn, P.R.; Ambihaipahan, N. Training in virtual environments: transfer to real world tasks and equivalence to real task training. Ergonomics, 2000, 43, 494-511.

38 Huygelier H, Schraepen B, van Ee R, Vanden Abeele V, Gillebert CR. Acceptance of immersive head-mounted virtual reality in older adults. Sci Rep 2019; 9(1): 4519 DOI: 10.1038/s41598-019-41200-6

39 Farley,O.R.L.;Spencer, K.; Baudinet, L.Virtual reality in sports coaching, skill acquisition and application to surfing: A review. Journal of Human Sport and Exercise, 2019. doi: 10.14198/jhse.2020.153.06

40 Ohl,C.D.;Dumke, R. Private Mitteilung.Details auf www.edu2vr.com,Private notice. Further information on www.edu2vr.com, 2018.

41 Geršak, G., Lu, H.; Guna, J. Effect of VR technology matureness on VR sickness. Multimedia Tools and Applications, 2018, 117. doi: 10.1007/s11042-018-6969-2

42 Sra,M. Asymmetric design approach and collision avoidance techniques for room-scale multiplayer virtual reality. Proceedings of the 29th Annual Symposium on User Interface Software and Technology, UIST '16 Adjunct, New York, NY, USA, ACM, 2016, 29-32.

43 Lampton, D.R.; Knerr, B.W.; Goldberg, S.L.; Bliss, J.P.; Moshell, J.M.; Blau, B.S. The 
virtual environment performance assessment battery (vepab): Development and Evaluation 1. Presence: Teleoperators \& Virtual Environments, 1994, 3(2), 145-157. doi: 10.1162/pres.1994.3.2.145

44 Guna, J.;Geršak, G.; Humar, I.;Kerbl, M.; Orel, M.; Lu, H.; Pogančnik, M. Virtual Reality sickness and challenges behind different technology and content settings. Mobile Networks and Applications, 2019. doi: 10.1007/s11036-019-01373-w

45 Lawson, B. Motion sickness symptomatology and origins. In: K.S. Hale, K.M. Stanney (eds.). Handbook of Virtual Environments (2nd ed.), 2014, $532-587$

46 Johnson, M;Humer,I;Zimmerman, B.; Shallow, J.; Tahai, L.; Pietroszek, K. Low-cost latency compensation in motion tracking for smartphone-based head mounted display. Proceedings of the International Working Conference on Advanced Visual Interfaces, New York, NY, USA, 2016, 316-317.

47 Abdel-Sater, K. A. Physiological positive feedback mechanisms. American Journal of Biomedical Sciences, 2011, 3(2), 145-155. doi: 10.5099/aj110200145

48 Sigrist R, Rauter G, Marchal-Crespo L, Riener $\mathrm{R}$, Wolf P. Sonification and haptic feedback in addition to visual feedback enhances complex motor task learning. Exp Brain Res 2015; 233(3): 909-925 DOI: $10.1007 / \mathrm{s} 00221-014-$ 4167-7

49 Lee S, Park Y, Zhang C. Exercise Training Prevents Coronary Endothelial Dysfunction in Type 2 Diabetic Mice. Am J Biomed Sci 2011; 3(4): 241-252 DOI: $10.5099 / a j 110400241$ 